\section{ESTIGMA TERRITORIAL COMO FORMA DE VIOLENCIA BARRIAL. EL CASO DEL SECTOR EL CASTILLO}

Catalina Andrea Cornejo ${ }^{1}$

\section{Resumen}

En el ámbito académico se expone la violencia como un problema asociado a los hechos delictuales en el ámbito ciudad, obviándose otras formas de violencia que operan en este contexto tales como la violencia simbólica. Ésta, aplicada a la comprensión de las realidades barriales de la ciudad de Santiago, hace posible observar en la configuración de estigmas territoriales, identidades deterioradas de carácter colectivo que se imponen sobre ciertos barrios de la ciudad, considerados reductos de delincuencia y pobreza.

En este contexto, el objetivo de este artículo es aproximarse al estigma territorial como forma de

\section{TERRITORIAL} STIGMATIZATION AS A FORM OF NEIGHBORHOOD VIOLENCE. THE CASE OF EL CASTILLO

Catalina Andrea Cornejo ${ }^{1}$ 
violencia simbólica a través de las percepciones de habitantes de un sector estigmatizado de la ciudad de Santiago de Chile, concretamente habitantes del sector El Castillo de la comuna de La Pintana.

Este artículo es producto de un estudio exploratorio y de carácter cualitativo, para el cual se realizaron 20 entrevistas semi-estructuradas. Entre los principales resultados se encuentran el reconocimiento de los habitantes de ser encasillados con estigma a condición de habitar un barrio determinado, por un lado, y la lucha de combatir el estigma creando una nueva identidad territorial, por otro.

\section{PALABRAS CLAVES: VIOLENCIA BARRIAL;} VIOLENCIA SIMBÓLICA: ESTIGMA TERRITORIAL.

Fecha de recepción: 11.11.11

Fecha de aceptación: 27.04.12

1 Antropóloga Social Universidad de Chile. Estudiante de Máster en Planificación Territorial y Gestión Ambiental. Universidad de Barcelona.Email: ccorneco7@alumnes.ub.edu.

178 revista invi № 76 / Noviembre 2012 / Volumen № 27: 177-200 the perceptions of dwellers of a stigmatized area of Santiago de Chile, more precisely, El Castillo, located in the borough of La Pintana.

This paper is the result of a qualitative exploratory study based on 20 semi-structured interviews. The main outcomes of this research are the awareness of dwellers about the stigma created around them because of living in a specific neighborhood on one hand and the fight against this stigma by creating a new territorial identity on the other.

KEYWORDS: NEIGHBORHOOD VIOLENCE; SYMBOLIC VIOLENCE; TERRITORIAL STIGMA.

Received: 11.11.11

Accepted: 27.04.12

Social Anthropologist, Universidad de Chile. MA Student in Territorial Planning and Environmental Management, Universidad de Barcelona. Email: ccorneco7@alumnes.ub.edu 


\section{Introducción}

Al hablar de violencia barrial se suele remitir a actos delictuales bajo el esquema víctima/victimario dentro de 'barrios críticos', los que concentran una diversidad de problemas sociales (delincuencia, drogadicción, desempleo, etc.). Esto tiene como contracara la práctica invisibilidad de otras formas de violencia que se manifiestan en este contexto, tal como lo que se comprende por 'violencia simbólica', esto es, una forma de coerción que impone significaciones como legítimas, ocultando las relaciones de fuerza desde donde surgen ${ }^{2}$. En otras palabras, a través de la violencia simbólica se impone un sentido común acerca del mundo social.

Aplicado esto a la observación de la ciudad de Santiago de Chile, reconocemos la configuración de estigmas, identidades deterioradas ${ }^{3}$ de carácter colectivo que se imponen sobre ciertos barrios de la ciudad, considerados desde la sociedad mayor como reductos de delincuencia y pobreza.

Antes de proceder con las líneas teóricas que sustentan el planteamiento de este artículo, se debe aclarar que no se pretende observar la internalización del estigma por parte de los sujetos en tanto fenómeno sicológico, ello va más allá del alcance de nuestros objetivos. Más bien, el interés es dar a

2 Bourdieu, 2001.

3 Goffman, 2006.

ARTÍCULO: Estigma territorial como forma de violencia barrial. El caso del sector El Castillo / Catalina Andrea Cornejo conocer la forma en que experimentan el estigma las personas a condición de vivir en un territorio determinado. Junto con lo anterior, el propósito mayor es la comprensión de este tipo de estigma como una forma de violencia barrial, producto de relaciones de fuerza que a pesar de su calidad 'simbólica' se territorializa en el espacio urbano de la ciudad de Santiago.

El estudio corresponde a una investigación de tipo exploratorio de carácter cualitativo. Para ésta se realizaron 20 entrevistas semi-estructuradas a habitantes de distintas poblaciones que conforman el sector El Castillo, en el transcurso del segundo semestre de 2008 y el primer semestre de 2009. Cabe señalar que la selección de entrevistados tuvo como filtro institucional la DIDECO $^{4}$ de $\mathrm{La}$ Pintana y el Centro Ambulatorio El Castillo de la ONG Paréntesis, cumpliendo criterios de diversidad etaria, de género y de ocupación.

La mitad de las entrevistas corresponde a material recogido para la memoria 'Segregación espacial y las prácticas espaciales de los excluidos. Estudio de caso: el sector El Castillo, de La Pintana', para la obtención del título de Antropóloga Social, de la Universidad de Chile, de quien firma este artículo. La mitad restante fue resultado de entrevistas de la Tesis Doctoral en Geografía y Planificación Urbana

4 Esta sigla hace referencia a las Direcciones de Desarrollo Comunitario, órganos dependientes de las administraciones municipales comunales en Chile.

revista invi № 76 / Noviembre 2012 / Volumen №27: 177-200 179 
de Alejandra Lazo, en la cual se colaboró en la recolección de datos. Con el permiso de la investigadora, el material de estas entrevistas ha sido incorporado. En ambos casos, los resultados han sido elaborados para fines de este artículo. Se realizó un análisis cualitativo de contenido, consistente en la definición de categorías que combinan la teoría y los datos recogidos.

En lo que respecta a los resultados, éstos muestran el reconocimiento del estigma de parte de los habitantes del sector. El Castillo se percibe como un territorio donde se concentran problemas sociales -como el tráfico y consumo de drogas- asociados directamente a las expresiones de violencia en el espacio público. Por otra parte, se observa que el estigma responde tanto a experiencias de discriminación vividas por algunos de los entrevistados como a imágenes que entregan los medios de comunicación, especialmente la televisión.

No obstante, los pobladores entrevistados muestran una relación ambivalente con la identidad impuesta, ya sea acusando la injusticia de ser encasillados bajo ésta, ya sea a través de la acción de las organizaciones comunitarias que incentivan el uso de espacios públicos, con el objeto de crear una nueva identidad territorial que los favorezca y represente.

180 revista invi № 76 / Noviembre 2012 / Volumen N ำ 27: 177-200

\section{Aproximaciones al fenómeno de la violencia}

Existe una abundante literatura que aborda la violencia como problema social, situándola especialmente dentro del contexto urbano actual. Se comprende que las ciudades constituyen un espacio privilegiado de su manifestación. Es más, la problemática de la violencia en la ciudad se confunde con la historia de los estudios urbanos, particularmente en el ámbito de la sociología con los estudios realizados por la Escuela de Chicago.

Hoy por hoy, dentro del ámbito académico latinoamericano, se han multiplicado los esfuerzos para esclarecer conceptualmente la violencia, donde encontramos definiciones del tipo "toda conducta humana que produce o amenaza con producir daño físico, psicológico y/o patrimonial a otros sujetos o a sí mismo" . De esta definición llama la atención que sitúa la violencia como una cuestión individual, siendo en ciertos casos potencia (produce daño) y en otros potencial (amenaza con producir daño).

En esta misma línea se inscriben otras definiciones como "conducta o amenaza creíble de provocar daño físico" "o "el uso o amenaza del uso de la fuerza

San Juan, 1999, en Lunecke, y Ruiz, 2008. s/p.

6 Oviedo, 2000, en Ruiz, 2008. 
física o sicológica con la intención de hacer daño"7. En la primera se restringe la violencia a la pura 'fisicalidad' de su manifestación, desatendiendo a la complejidad de este problema. En la segunda, se destaca positivamente el reconocimiento de una dimensión no física de la violencia y el carácter intencional de esta relación. Por otra parte, la violencia estaría orientada concretamente a hacer daño. Leyendo entre líneas, esta intencionalidad respondería a cuestiones emocionales (aun cuando estos autores reconocen otros 'fines' de la violencia, por ejemplo, el control de los recursos económicos del hogar en el caso de la violencia doméstica ejercida sobre la mujer).

Las nociones precedentes no nos parecen suficientes para entender el fenómeno. De nuestra consideración, 'hacer daño' más bien debería entenderse como una de las manifestaciones de la violencia. Comprendemos que ésta puede obedecer tanto a necesidades de expresión como a la racionalidad en términos de medios ajustados a fines. Ello se aplica también para el caso de la violencia simbólica, que sirve a los fines de legitimización del orden social (no propiamente hacer daño).

Más cercano a nuestra óptica encontramos el concepto "relación de fuerza o poder que surge de intereses y poderes que no encuentran soluciones distintas a la fuerza"8. A pesar de que esta definición tiene

7 Buvinic et al, 1999 en Buvinic; Morrison y Orlando, 2005, p. 42.

8 Carrión, 2003, p. 33. cierto carácter negativo, tiene de sugerente el entendimiento de la violencia como una cuestión relacional referida al ejercicio del poder entre los sujetos.

Como hemos visto, actualmente en los estudios sobre la violencia se destacan los hechos delictuales como su principal manifestación. No obstante, han surgido planteamientos críticos que relacionan el origen de la violencia con las condiciones mismas del sistema capitalista, comprendiendo además la relevancia actual de la violencia física como efecto de la imposición de un discurso dominante que oculta justamente las causas socio-históricas del fenómeno.

Ejemplo de ello es Zizec, quien distingue tres tipos de violencia estrechamente relacionadas. En primer lugar, la violencia subjetiva que resulta de la perturbación de un supuesto estado normal de las cosas. Este tipo violencia supone su visibilidad, así como también su imputabilidad a sujetos particulares -aquí podemos situar a la violencia física, a la que se reduce la comprensión actual pública-. Como contraparte, existiría una violencia objetiva o sistémica referida a la lógica de producción y reproducción del sistema (capitalista), en el que encuentran las causas la pobreza y la desigualdad social. La eficacia de esta violencia radicaría en su práctica invisibilidad y anonimato para los sujetos. 
Finalmente se define la violencia simbólica referida a la imposición de los discursos hegemónicos acerca de la realidad social ${ }^{9}$.

Una consecuencia importante de este planteamiento para nuestro objetivo, es el reconocimiento de la transversalidad de la violencia simbólica, en cuanto revela y hace visible un tipo de violencia (subjetiva) al tiempo que omite, excluye y desplaza así la visibilidad de otra (la sistémica).

En esta misma línea encontramos a $\mathrm{Olmo}^{10}$, quien realiza una crítica acerca del tratamiento teórico de la violencia. Sin dar una definición propia, la destaca como concepto político. De acuerdo a este planteamiento, las variadas manifestaciones de la violencia son destacadas (u omitidas) en el ámbito público de acuerdo a factores históricos. Hoy en día se resaltaría la asociación de la violencia a la delincuencia, así por razones de rigurosidad conceptual esta autora prefiere hablar en términos de 'criminalidad violenta'.

En este punto cabe preguntarse qué entenderemos por violencia en el transcurso de este artículo. Para esto nos hacemos eco de las consideraciones anteriores (Zizec; Olmo), resaltando en primer lugar que la distribución desigual de poder en una sociedad es uno de los factores principales de la manifestación de la violencia, ello porque esta misma

$9 \quad$ Zizec, 2009

10 Olmo, 2000. constituye relaciones de fuerza (poder) ejercida entre sujetos. Su manifestación a diversos fines se expresa en distintos niveles, ya sea físico, psicológico, simbólico, etc. En este sentido, es un fenómeno complejo y multidimensional, razón por la cual consideramos errado identificarla con su expresión física y con el problema de la delincuencia común.

Para trascender esta visión reduccionista de la violencia, debe comprenderse bajo la consideración que las mismas relaciones sociales en que se funda la violencia imponen ciertos niveles de visibilidad y legitimidad social.

\section{Violencia simbólica}

Hemos planteado que la violencia no se agota en el fenómeno de la delincuencia ni viceversa, a pesar que esta asociación destaque en la academia y en la opinión pública. Entre las manifestaciones de violencia nos preocupa especialmente la de carácter simbólico comprendida como "todo poder de violencia simbólica, es decir, todo poder que logra imponer significados e imponerlos como legítimos disimulando las relaciones de fuerza en las que se basa su fuerza, agrega su propia fuerza, es decir, una fuerza especificamente simbólica, a estas relaciones de fuerza"11. Esto es, una forma de coerción que

11 Bourdieu, 2001, p. 4 
impone significaciones como legítimas, ocultando las relaciones de fuerza desde donde surgen.

En cierto sentido, la violencia simbólica es cercana a la idea de violencia de la clásica definición de Webber del Estado, donde éste se comprende como la institución con el monopolio del ejercicio legítimo de la violencia ${ }^{12}$. Sin embargo, no podemos reducir la violencia 'legítima' sólo a las acciones de los aparatos estatales (instituciones militares, policiales, etc.), ni la violencia simbólica a la ejercida por el Estado.

La violencia simbólica converge con otros tipos de violencia, en tanto da fundamento a las relaciones de poder de una sociedad determinada, teniendo como consecuencia que sobre quienes se ejerce el poder, legitimen su condición de subordinación. De cierta manera, la violencia simbólica imponiendo un discurso apela a los sujetos ${ }^{13}$.

En última instancia, la violencia simbólica implica la naturalización de la realidad social y, complementariamente, el oscurecimiento de las relaciones de poder en que se funda el orden social.

12 Podemos, por tanto, responder afirmativamente a la pregunta planteada por Ruiz (2008), ¿la violencia ejercida por los agentes del Estado, el monopolio legítimo de la violencia y su aplicación cotidiana por parte de la policía, es también una forma de violencia?

13 Al modo de la ideología tal como fue definida por Althusser, destacamos la evidente relación con este concepto. Sin embargo, la discusión sobre el concepto ideología es tan amplia que preferimos soslayarla para no desviarnos de nuestro objetivo.
Con este concepto destacamos el origen relacional de la imposición de la violencia, que ya no depende de las características, acciones y/o actitudes atribuidas al grupo sobre quien se ejerce la violencia, sino también de quienes la ejercen. Eso es claro cuando hablamos de violencia física de cualquier tipo, pero no lo parece cuando hablamos de violencia simbólica y de la estigmatización como una de sus expresiones. Se muestra entonces insuficiente el esquema víctima/victimario. Quizás ello se deba en parte a que las características de la violencia simbólica ocupa una posición intermedia entre la visibilidad y el anonimato, al ser parte de prácticas discursivas de los sujetos, pero difícilmente referida a sujetos particulares como agentes de la violencia -aun cuando se concrete en prácticas sociales particulares-, sino al todo social ('la sociedad mayor'). Esto mismo debe atribuirse a su condición de violencia que sirve a los fines de legitimidad social. En lo que respecta al estigma propiamente tal, este concepto remite a identidades sociales deterioradas, que no son razón de orgullo ni valía personal para quienes son categorizados por medio de 
éste ${ }^{14}$. A nivel más general y global, el estigma refiere a la construcción de la alteridad, de tal manera que se constituyen 'otros' que escapan de la noción de lo que es establecido como normal en una sociedad. Por otro lado, el estigma parece subsumir cualquier otra categoría social de los sujetos, enclaustrando identitariamente a quienes se les identifica con éste.

Comprendemos que la construcción de estigmas -estigmatización- es una expresión de violencia (simbólica) en la medida que se impone, se constituye a través de relaciones de fuerza. Por otro lado, los criterios por los cuales se estigmatiza a ciertos individuos o grupos no obedecen a un orden natural de las cosas, sino a cuestiones culturales y, en tal sentido, son arbitrarios. No obstante, justamente la eficacia del estigma yace en presentarse como un contenido natural.

El carácter arbitrario que reconocemos en el estigma no implica que no haya -si se permite la expresión- una 'base objetiva' en que se funde el origen del estigma. Éste se aplica sobre algunos sujetos y/o grupos que ocupan posiciones sociales marginales dentro de la sociedad. Es más, el estigma puede constituirse en función de la falta de capital económico y simbólico como el caso que abordaremos en este artículo, más allá de las enfermedades y defectos físicos especialmente tratados por Goffman en su libro.

14 Goffman, 2006.

184 revista invi № 76 / Noviembre 2012 / Volumen No 27: 177-200
De acuerdo a Link y Phelan ${ }^{15}$, el estigma nace de la convergencia de 5 elementos: i) la capacidad de distinción y categorización de las diferencias entre los seres humanos, ii) las creencias dominantes acerca de lo indeseable, las cuales son posibles de transformarse en estereotipos negativos, iii) la construcción de la alteridad, iv) la pérdida de estatus y discriminación de los estigmatizados y v) las relaciones de poder de las cuales la estigmatización es completamente contingente.

En esta perspectiva se comprende que la selección de las diferencias, como base de la estigmatización, estaría dada 'por el proceso social', a través del cual se llegaría a la naturalización de las diferencias -'taken-for-granted nature'-.

Estos autores prefieren hablar de etiqueta en vez de atributo, condición o marca porque cada uno de estos términos localizan e individualizan lo que está siendo referido a los sujetos estigmatizados, bajo el riesgo de oscurecer el proceso social que está detrás de la estigmatización. De esta manera se comprende la aserción que "la impugnación de determinados grupos o individuos como marginales, problemáticos o desviados no está motivada sólo por lo que éstos hagan o dejen de hacer, sino también por la mirada social que excluye de las propias fronteras culturales y simbólicas a todos aquellos que son vistos como extraños"16.

15 Link y Phelan, 2001.

16 Campo Tejedor, 2003, p. 804. 
En lo que respecta a la relación del territorio con el estigma, de acuerdo a las concepciones teóricas de Wacquant, ésta conforma uno de los cuatro elementos constitutivos del gueto como forma de organización socio-espacial, junto con la restricción, el encapsulamiento institucional y el confinamiento territorial. De tal manera que la concentración de un grupo social en un territorio se identificaría con la de confinamiento espacial, realizada a través del abandono de zonas céntricas como en U.S.A., o en el traslado de los pobres a zonas periféricas, como ocurrió en Chile; el repliegue se asociaría a la restricción espacial, y la idea de estigma territorial justamente con la creación de una identidad socio-territorial negativa.

Particularmente para el caso del sector El Castillo existe un estudio ${ }^{17}$ que lo analiza bajo estos elementos $^{18}$. No es propósito de este artículo categorizar como guetos a este sector ni a otros barrios pobres de la ciudad de Santiago, se requeriría una investigación completa dedicada a ello ${ }^{19}$. A simple vista, en el gueto y el barrio pobre periférico se

17 Traverso, 2006.

18 Cuando Wacquant (2004) define el gueto, comprende que la segregación espacial, si bien necesaria, no es suficiente para su surgimiento. Por otra parte, alude a la etnia y a la raza que, como criterios por los que operan la exclusión, no tendrían como contenido exclusivo ni necesario la pobreza. Por ello, nos alejamos de la consideración del sector El Castillo o cualquier otro barrio pobre y estigmatizado de la ciudad de Santiago de Chile como un gueto bajo el concepto de Wacquant, por lo menos hasta nuevos estudios.

19 Sabatini et al, 2010 observan condiciones y características diferentes en su desarrollo y consecuencias. Sin embargo, podemos reconocer que el sector El Castillo, como barrio periférico pobre de la ciudad de Santiago al igual que los guetos, sufre de un proceso de estigmatización territorial, "una modalidad distintiva de descrédito colectivo que cargan los habitantes de vecindarios de confinamiento espacial"20.

El estigma condensa una serie de contenidos negativos de los individuos o grupos que se postulan como naturales y evidentes por sí mismos. Reconocemos en él las fuerzas de la violencia simbólica en la medida que es impuesto y que quienes lo sobrellevan tienen poca capacidad de constituir una identidad social diferente a la impuesta.

En el caso estudiado, El Castillo se comprende como una síntesis de pobreza, delincuencia y violencia. El estigma aquí es resultado de violencia que se ha territorializado gracias a procesos de confinamiento espacial de los pobres de la ciudad mediante las políticas de estado, durante la dictadura

20 Wacquant, 2001, p. 16 
militar. Este punto de origen ha supuesto la imposición de significaciones, contenidos e imágenes acerca de este territorio específico y de quienes lo habitan. Es así comprensible como una forma de violencia barrial en tanto impone prácticas y discursos de quienes son estigmatizados por el sólo hecho de habitar este barrio.

\section{Contextualización del sector El Castillo}

El sector El Castillo se encuentra ubicado al sur oriente de la comuna de La Pintana, enmarcado por la avenida Batallón Maipo al norte, avenida La Prima al sur, avenida Santa Rosa al oeste y avenida La Serena- Carretera Acceso Sur al oriente.
Destaca la comuna de La Pintana por su marcada homogeneidad social. La distribución de grupos socioeconómicos de acuerdo a datos del Censo de 2002 muestra que un 55,1\% pertenece al sector D y $20,7 \%$ al sector $\mathrm{E}$, los que corresponden de manera respectiva a la clase media baja y clase baja ${ }^{21}$.

Por otra parte, el nivel de ingreso de los hogares en la comuna está por debajo del nivel metropolitano, asimismo las mediciones de empleo anuales (para junio de cada año) son menores que la media metropolitana. Un dato contundente respecto a la homogeneidad social es que el $98 \%$ de las viviendas son de carácter social (de un total de 47.000 viviendas). ${ }^{22}$ Esto se explica principalmente por su origen en las políticas de vivienda social de las últimas décadas.

Para el caso del sector El Castillo, el diagnóstico de la situación de pobreza ${ }^{23}$ hecho por la SECPLAC de

21 Habitualmente en Chile los grupos socioeconómicos se clasifican en $A B C 1, C 2, C 3, D$ y $E$, que correlativamente son: la clase alta, clase medio alta, clase media, clase miedo baja y clase baja, estableciéndose como variables indicativas del NSE el nivel educacional del jefe de hogar [sin estudios, Básica incompleta, Básica completa, Media incompleta, Media completa, Técnico incompleto (1 a 3 años), Universitaria incompleta o técnico completa, Universitaria completa o más] y la tenencia de ciertos bienes [TV color, ducha, refrigerador, lavadora, calefont, microondas, automóvil, TV cable o satelital, PC e internet].

22 SECPLAC, 2012.

23 SECPLAC es la sigla con las que se conocen las secretarías comunales de planificación, órganos dependientes de la administración municipal en Chile para la planificación territorial local. 
La Pintana ${ }^{24}$ muestra que un 3,38\% de hogares están en situación de pobreza crítica, 11,40\% en pobreza inercial y $9,01 \%$ en pobreza reciente. Sumando un total de $23,82 \%$ de hogares pobres y presentando así el mayor porcentaje de pobreza de la comuna.

Actualmente El Castillo alberga una población aproximada de 37.985 habitantes que corresponden al 20\% de la población comunal, equivalente a 191.743 habitantes $^{25}$. Constituye uno de los tres sectores administrativos (junto a El Roble y Santo Tomás) que son producto mayormente de la erradicación de campamentos ${ }^{26}$. En el sector existen 15 poblaciones, 8 de las cuales se conformaron con población erradicada en la dictadura: Jorge Alessandri I y II, Estrecho de Magallanes, Ignacio Carrera Pinto, Eleuterio Ramírez, Santiago de Nueva Extremadura, Nueva Patagonia y Villa Ombú, donde fueron instaladas 31 mil personas (5.969 familias) en el período 1979-1987.

24 SECPLAC, 1995, en SECPLAC, 2012.

25 SECPLAC La Pintana, 2009.

26 Denominación con que se conocen en Chile los asentamientos informales.

\section{LA ERRADICACIÓN DE CAMPAMENTOS COMO UN HECHO FUNDANTE}

Desde mediados del siglo XX en Santiago de Chile se adoptaron diversas medidas para dar 'solución habitacional' a los pobladores de asentamientos precarios. Entre éstas destacó la erradicación de campamentos, la que se suele identificar con su período de aplicación durante la dictadura militar ${ }^{27}$.

Comprendemos que la erradicación concretizó en el territorio la lógica de expulsión ${ }^{28}$ bajo la doble determinación del estado, el que proporciona una base legal a dichas erradicaciones -a lo que habría que agregar la represión política de la época-, y del mercado, convertido desde entonces en el principal agente en la asignación de vivienda social.

Concretamente, en el período de 1979-1985 se llevó a cabo el programa relocalizando a los habitantes ilegales de comunas del centro oriente de la

27 Cabe destacar que la relocalización de campamentos en los gobiernos precedentes a la dictadura difiere tanto cuantitativa como cualitativamente de esta última. Ello debido en parte a la mayor cobertura de familias erradicadas en dictadura y la 'colonización' de extensos territorios que no pertenecían ni estaban conectados al área metropolitana de Santiago. A ello se suman las diferencias en los fundamentos que orientaron la política y sus consecuencias a nivelterritorialy social, aún hoy observables. Por esta razón hacemos el corte histórico en la dictadura y no antes.

28 Esta lógica de expulsión puede verse contradicha por la llegada de grupos medios y altos registrada en comunas pobres, pero, como hemos afirmado anteriormente, éstas son aledañas a las comunas de residencia tradicional de las clases altas. De cualquier modo, tal situación pone de manifiesto la predominancia del mercado en la gestión urbana. 
ciudad hacia el sector sur y poniente de la capital. Este proceso definió el crecimiento de las 'comunas receptoras ${ }^{29}$, especialmente La Granja, donde la actual comuna de La Pintana formaba un sector más, donde se localiza a su vez El Castillo.

Antes de la erradicación, el sector conformaba parte de un fundo que fue adquirido a principios de la década del 80 por la municipalidad de Santiago centro para la relocalización de habitantes de campamentos $^{30}$, momento en que se gesta su poblamiento y empieza a transformarse en un territorio emblemático del proceso de erradicación.

Actualmente, a pesar de la existencia de poblaciones $^{31}$ no construidas por la erradicación, dicho programa de erradicación ha servido para comprenderlo como un territorio unitario marcado por la expulsión desde el centro de la ciudad. Además, este hito remarca un origen precario por la misma extracción social de los pobladores ya estigmatizados en su condición de pobres y habitantes de campamentos.

\section{Resultados}

\section{CONFINAMIENTO TERRITORIAL}

El relativo confinamiento espacial de los habitantes ha ayudado a la configuración de un sentido común respecto a la experiencia de habitar el territorio. A nivel del discurso, se han cristalizados códigos compartidos, como la denominación misma del sector (El Castillo) que se superpone sobre el nombre de las poblaciones y villas; también las denominaciones del sector como 'pueblo sin ley', 'las Malvinas', 'el lejano oeste', que condensan los contenidos de violencia y delincuencia.

Estas metáforas surgieron durante los primeros años de la formación del sector, cuando la precariedad del asentamiento y la desarticulación social de los campamentos, entre otros factores, supusieron manifestaciones de violencia entre los recién llegados.

"Porque cuando nosotros llegamos a la población no se podía vivir, no era buena. Aqui la gente tenía que proteger las ventanas con madera o con latas, porque

\footnotetext{
29 Labbé y Llévenes, 1986.

30 Rodríguez e Icaza, 1993.

31 Denominación que hace referencia a los conjuntos habitacionales de las clases bajas en Chile.
} 
cuando nosotros llegamos aquí, le llamaban 'Las Malvinas' a esta población”. I., dueña de casa.

“(...) Aquí sobrevive el más fuerte... Esto antes lo llamaban el 'pueblo sin ley' (...) Ya a las 6:00 de la tarde teníamos que andar poniendo protección en las ventanas, unas tarimas y cuestiones, porque se juntaban bandos de aquí, bandos de allá, métale balazos y cuestiones". S., pensionada.

"Es que una está acostumbrada a esta rutina, una lleva así más de 20 años, lleva años ya, entonces está más acostumbrada, por allá no se siente un balazo, no se siente una pelea, no se siente ni los niños jugando en la calle. Entonces, como que una está acostumbrada a esta rutina aquí. Al festival de balas, porque aqui hay festival, la mayoría de las noches puro festival". T., dueña de casa.

\section{AUTOPERCEPCIÓN DE LA CONDICIÓN DE EXCLUIDOS}

Se identifica entre los habitantes de El Castillo la percepción de pertenecer a una categoría excluida. Ello corresponde a la dimensión subjetiva de la segregación espacial ${ }^{32}$, que es referida como un elemento constitutivo de dicho fenómeno como consecuencia de la exclusión social. Entre los entrevistados esta percepción es visible particularmente en el reconocimiento del estigma territorial que pesa sobre El Castillo y que, por extensión, se aplica sobre ellos como sus habitantes.

32 Sabatini et al., 2001.
Esta percepción se ha construido gracias a experiencias de discriminación vividas por algunos de los entrevistados o de conocidos por vivir en el sector (o la comuna de La Pintana), y también por las imágenes sobre el sector que entregan los medios de comunicación, especialmente la televisión.

"La comuna de La Pintana igual es como súper discriminada en cuanto a seguridad y cosas así, pero no todo es así, (porque) hay buenos y malos en todos lados (...) Yo quiero salir de acá de la comuna (...), por la seguridad, también por el trabajo, hay partes que he ido a postular, uno dice la comuna, no te lo dicen, pero, el currículum te lo pasan para abajo (...), o sea, la discriminación está (...). Yo, de hecho, en mis currículo no le pongo La Pintana, yo le pongo Puente Alto, puede que Puente ande por ahí, pero, para mí pesa más que La Pintana". A., estudiante de educación superior técnica.

"Normalmente, hay gente como se dice en El Castillo, como en todos los lados, pero, hay gente que con la droga... como le estoy diciendo (...) porque uno no puede decir... no puede meter a todos al saco, meter así a la misma gente, si hay dos, tres, cuatro personas y una que sea la manzana podrida, que decimos nosotros, y esa está echando a perder a la otra gente". M., comerciante y presidente de una junta de vecinos.

"La caracteriza la delincuencia, pero, no to'o, porque no hay que generalizar, porque sé que son pocas las 
personas, nosotros somos gente normal, no somos esa gente que anda robando, que por unos pocos se echa a perder toda la comuna". M., estudiante secundario.

"Uno va a otros lados, como que esta población es lo último, el extracto de todo el cachureo, que nunca uno puede conseguir nada (...), hay tanta gente que a uno la mira en (menos), no la mira como tiene que ser. Cuando recién llegamos aquí, de primera siempre íbamos al centro, porque yo tenía mis tarjetas de crédito, íbamos a solicitar, póngale, otra tarjeta y dirección nos quedábamos así, porque al nombrar La Pintana, 'No, señora, no se puede', era como muy denigrante nombrar que uno vivía en La Pintana, ya caíamos dentro del saco, y no es así, aquí hay mucha gente de trabajo". M., dueña de casa.

"Porque nos echan, como se dice vulgarmente, 'en el mismo saco'. Y aquí hay gente mala como hay gente buena, pobre, pero decente. Porque aqui no hay gente rica-rica como se dice. Gente de trabajo y esos son los que alimentan a los que... eligen cuando saben que les pagan para esperarlos a las micro (sic)". S., pensionada.

190 revista invi № 76 / Noviembre 2012 / Volumen № 27: 177-200

\section{“COTIDIANIZACIÓN" DE LA VIOLENCIA}

Para los pobladores, los años de residencia han conllevado un gradual proceso de configuración de dinámicas propias, asumiendo las manifestaciones de violencia en el territorio como una cuestión cotidiana estrechamente ligada al estigma territorial.

De acuerdo a las entrevistas, las características con que se identifica El Castillo aluden especialmente a problemas sociales como el consumo de drogas y narcotráfico, asociados a acciones violentas entre vecinos en el espacio público, más que violencia interpersonal doméstica (secundariamente le siguen el desempleo y las bajas expectativas de vida).

Los entrevistados reconocen la existencia de distintos grupos compuestos principalmente por hombres jóvenes que realizan actividades ilícitas como el consumo y tráfico de drogas y utilizan la vía pública para tales actividades, incluyendo en ocasiones enfrentamientos violentos. Algunos de dichos grupos son compuestos por hinchas de fútbol que agrupan a simpatizantes del equipo ColoColo o de Universidad de Chile, existiendo otros 
dedicados abiertamente a actividades delictivas como 'Los Vatos Locos'33.

"Es que hay mucho tráfico, el tema de las peleas, de bandos, es algo de todos los fines de semana, pa' llá pa' cá, los balazos, una no puede estar tranquila en la calle". J., estudiante secundaria.

"Donde vivo yo siempre hay problemas, siempre hay problemas, balaceras, robo, no se puede andar tranquilo en las noches”. M., estudiante secundario.

"De repente hay vecinos que tienen mal vivir, en qué sentido, en que de repente, tú trabajas de noche y quieres puro dormir, pero están en la mañana con la bulla, ¿me entendí?, lo típico, las peleas por violencia, por alcohol, los cabros se amanecen, después hay peleas y andan reclamando que a mi cabro le pasó esto, pero, ¿y la mamá dónde estaba?, lamentablemente, es la misma gente, cachai, no todos son malos, pero como que la misma gente echa a perder todo lo buena onda, cachai, o sea, yo te digo, tú vas para allá pa' dentro es como otras expectativas de vida (sic)". A., estudiante de educación técnica superior.

"Igual lo que más destaca de la población es la violencia, aquí no hay noche si no hay balazo, ¿cachai o no? (...), el sector mismo nos hace ser más duro, en forma de pensar, incluso ser más agresivo, porque si no soy asi aqui te pasan a llevar poh, no puedes dejarte pasar a llevar por nadie aqui, porque si te dejas pasar a llevar te van a comer". P., guardia de seguridad de un supermercado.

"Hay días en que es peligroso, hay mucha droga pa' dentro, esa cuestión que tiene botada a la gente, la juventud sobre todo, tengo una tesis, yo también recorro por ahi, es que me dicen que venden (...) i $P^{* * *} a$ que hay cualquier problema en estas poblaciones!, la droga primero, la cesantía también es otro problema, preguntas: ¿Está trabajando? - No. Le preguntas a otro: ¿Estás trabajando? - No, estoy haciendo pololos, o soy comerciante o soy comerciante ambulante, eso poh. Los

33 La denominación fue adoptada por este grupo en base a la película 'Sangre por sangre', *1993 de Taylor Hackford (título original: 'Blood in, blood out'), que trata sobre pandillas juveniles. Justamente los protagonistas pertenecen a un grupo llamado Vatos locos. Anteriormente, en la ciudad de Santiago varios grupos de jóvenes inspirados en la cinta han tomado la denominación, como en el cerro 18 de la comuna de Lo Barnechea, en la población San Francisco de Asís de Puente Alto, o como en este caso, en el sector El Castillo. Este grupo fue detenido en marzo de 2010, 'formalizado por los delitos de infracción a la Ley de Armas, homicidio frustrado, tráfico de drogas y asociación ilícita'. (Cleiva, 2010). 
colegios, mucho que los niños no estudian, se salen del colegio porque hay papás que no son capaces de comprarles los cuadernos, por lo mismo por el trago, por la droga". M., comerciante y presidente de una junta de vecinos.

Por otra parte, las expresiones de violencia son ubicadas en una temporalidad propia: las noches y los fines de semana. No obstante, la violencia parece desbordar el día a día, más allá de la ocurrencia efectiva de violencia delictual, porque forma la identidad del territorio.

\section{LUCHA CONTRA EL ESTIGMA: CAMBIARLE LA CARA AL SECTOR}

El proceso de estigmatización supone ciertos niveles de internalización de la identidad de parte de los sujetos estigmatizados. Así se encuentran quienes reivindican los contenidos del estigma como cuestiones positivas, revalorando las acciones violentas como legítimas. Como contraparte, se vislumbran en nuestro estudio e indirectamente en el caso del mundo evangélico ${ }^{34}$, estrategias que potencian nuevas identidades para romper con el estigma territorial, intentando apelar a otros contenidos identitarios.

El estigma es combatido en el plano discursivo denunciando la injusticia de ser encasillados bajo

34 Véase los estudios de Abarca y Sepúlveda, 2001 y Montecino, 2002.

192 revista invi № 76 / Noviembre 2012 / Volumen No 27: 177-200 éste, lo que se expresa coloquialmente con 'ser echados en un mismo saco'. Este hecho es comprendido injusto, al no dar cuenta de la diversidad de modos de vida que existen en contextos de pobreza. En última instancia, es un intento de reivindicación de su calidad moral (la pobreza honrada) y, de cierta manera, de inclusión reconociéndose partícipes de los valores sociales de la sociedad mayor.

Por otra parte, el estigma se combate a nivel de las prácticas, a través de la acción de las organizaciones comunitarias que incentivan el uso de espacios públicos mediante la realización de actividades culturales y recreativas con el objeto de romper la imagen negativa que pesa sobre el sector $y$, al mismo tiempo, crear una nueva imagen donde puedan reconocerse. La idea es que estas acciones puedan trascender el ámbito local y sean motivo de reconocimiento a nivel general de la ciudad.

"Es lo que así se está haciendo ahora en las plazas. Como yo soy integrante del CVD (Consejo Vecinal de Desarrollo), es lo que se está trabajando ahora. Se van a empezar a arreglar plazas que estaban en malas condiciones, hacer nuevas plazas, hacer más áreas verdes. Gente que se tomó el terreno de la pública hasta la casa, le pusieron árboles, pasto, pero cerraron pa' ellos, pero, para la demás gente... Entonces, esas rejas tienen que sacarlas (...). Ahora van a pavimentar todo lo 
que es Inés de Suárez también". O., dueña de casa y presidenta de un club social.

"(Queremos) recuperar espacios públicos porque dentro de la comuna se perdieron y cambiarle la cara al sector, más allá de que sea un sector público, hay gente que no quiere que sea así con ganas. Pero no se dan los mismos espacios. De hecho el año pasado [2008] vino una compañía de teatro al aire público y se llenó (...) eso demuestra que la gente tiene ganas de participar de otro tipo de actividades, sólo que no se realizan y parte de (el colectivo) es difundir la cultura que está completamente perdida en el sector, conseguirse una compañia de estudiantes de teatro que lo hagan gratis (...) pedirles que muestren su arte, que la gente lo pueda disfrutar". O., dirigente de un colectivo cultural.

"La violencia está en todos lados ahora (...), eso me motiva a trabajar en organizaciones y agrupaciones, porque me da pena ver cabros chicos de la edad de mi hermano chico metidos en la pasta, así robando, y domesticándose plantas (de marihuana), me motiva asi darle una ésta (cara) diferente a La Pintana, que no sea tan estigmatizada por lo demás, supuestas por las noticias". P., guardia de seguridad de un supermercado.

En su intento de construir una nueva identidad territorial mediante nuevas prácticas espaciales, principalmente a través de actividades culturales

ARTÍCULO: Estigma territorial como forma de violencia barrial. El caso del sector El Castillo / Catalina Andrea Cornejo y recreativas [tocatas, campeonatos de fútbol, etc.], la acción de estas organizaciones apelan a la configuración de 'espacio público' en su sentido cultural y político como referente de identidades colectivas y lugar de expresión del conflicto por el control del espacio entre distintos actores del sector ${ }^{35}$, más allá de un sentido físico del término. Es decir, se trata de configurar un espacio de reconocimiento social que en parte es negado cuando se los estigmatiza.

En este marco comprendemos que la internalización del estigma no es una cuestión pasiva ${ }^{36}$, ya que supone resistencias, inversiones de sentido de parte de los sujetos estigmatizados. Es más, se reconoce una tensión entre la identidad territorial configurada bajo los contenidos de violencia, delincuencia y pobreza, la experiencia cotidiana (en que se viven ocasionalmente situaciones de violencia delictual y violencia doméstica) y la necesidad de configurar una identidad como "la expresión de lo que da sentido y valor a la vida del individuo. Es al tornarse expresiva de un sujeto individual o colectivo que la identidad depende, vive, del reconocimiento de los otros: la identidad se construye en el diálogo y el intercambio, ya que es ahi donde individuos y grupos se sienten despreciados o reconocidos por los demás"37

Más aún, cuando existe cierta heterogeneidad social referida a la posesión de capital social y cultural

35 Borja y Muxí, 2003.

36 Campo Tejedor, 2003.

37 Barbero, 2002. p.17. 
que orienta modos de vida diferenciados, a pesar de los indicadores socioeconómicos que permiten clasificar a grandes rasgos a habitantes de El Castillo. Esta heterogeneidad se traduce en distintos recursos de carácter material, social y simbólico de posesión de los sujetos, que convergen en prácticas y representaciones sociales (habitus) que se ponen en contradicción con las imágenes homogenizantes del estigma.

\section{Conclusiones}

Los resultados aquí presentados constituyen una pequeña muestra de los habitantes del sector El Castillo. A pesar de esta limitación, nos dan pistas acerca de cómo se experimenta el estigma territorial en tanto forma de violencia y orientan sobre la relación entre ésta y el territorio. Nos parece claro que quedan pendientes por abordar diversos aspectos del estigma con otros grupos sociales habitantes del sector que por los alcances del estudio no lograron ser visibles. Por ejemplo, grupos que reivindican el estigma y lo asumen como parte de su identidad ${ }^{38}$.

Dentro de las principales conclusiones destacamos:

1. En este caso, primeramente la violencia se observa en la conformación histórica del sector. Aun teniendo muchas veces el beneplácito de la

38 Abarca y Sepúlveda, 2005. relocalización de parte de los habitantes por la obtención de viviendas, se deben considerar las condiciones mismas de dicha relocalización y el contexto de represión en que ésta se llevó a cabo como fruto de la violencia política durante la dictadura militar.

2. En un segundo orden, la violencia como experiencia cotidiana cobra un nuevo sentido, ya no restringida a los hechos delictuales en el espacio público (criminalidad violenta) o remitida a la violencia doméstica, sino también como una categoría social impuesta, como estigma territorial.

Apuntando a la relación entre la violencia simbólica y el territorio, vemos que el estigma territorial demarca al mismo tiempo identidades colectivas y geografías imaginarias de la ciudad, impuestas a través de relaciones de fuerza. En este aspecto, es pertinente hablar del estigma territorial como violencia.

3. Por otra parte, reconocemos que la poca visibilidad del proceso de estigmatización territorial como violencia tiene que ver con las relaciones de poder en contexto de desigualdad, exclusión social y segregación espacial de la ciudad de Santiago. En este ocultamiento reside justamente la fuerza de la imposición de la violencia simbólica por medio del estigma. 
4. El estigma territorial en cierto sentido constituye una falacia por la cual se asume que las prácticas delictuales y violentas de algunos habitantes son aplicables para comprender el conglomerado territorial, en nuestro caso El Castillo. En este mismo sentido, se establece una relación metonímica entre quienes realizan actividades delictuales y el territorio que habitan. Una vez constituido el estigma que homogeniza el territorio, se invierte esta relación, el todo -El Castillo- definido como territorio lleno de violencia y delincuencia, es identificable e identificado en cada uno de quienes habitan el sector.

5. El carácter territorial de esta identidad le confiere características especiales respecto de otros estigmas. Su inscripción en el territorio lo hace ubicuo y le da una relativa fijeza, dificultando la capacidad de los sujetos de escindirse de él. Es más, hay quienes internalizan y reivindican los contenidos del estigma. Esto puede comprenderse en parte como uno de los efectos de la inercia del espacio ${ }^{39}$, que supone la naturalización y reproducción del orden social en la medida que éste se reifica en el espacio físico.

No obstante, ello no debe llevar a asumir la pasividad de los sujetos estigmatizados. Como hemos observado, existen ciertos niveles de resistencia a ser encasillados bajo una identidad negativa no

39 Bourdieu, 1997. sólo a nivel discursivo, sino también a través de la ocupación del territorio.

6. La inscripción territorial del estigma se refuerza por el relativo aislamiento espacial que experimentan los habitantes de El Castillo, el que aún no siendo total, dificulta instancias de interacción que tienen los sujetos con individuos de otras categorías sociales, y cuando ello ocurre son especialmente de carácter funcional -trabajo, consumo-, no instancias de sociabilidad. Así, el relativo aislamiento favorece las interacciones sociales entre los mismos habitantes y la conformación de modos de vida sui géneris ${ }^{40}$. Cuestión que no debe conducir al error de considerar que los modos de vida están aparentemente determinados por una especie de condición biológica (natural) o por la geografía, sino comprenderlos como variables, ya sea a nivel sincrónico comparando los modos de vida entre las distintas familias que habitan el lugar, ya sea a nivel diacrónico en donde es visible el cambio social.

7. Finalmente, nos queda por relevar el rol de los medios de comunicación que tienden a comunicar y reproducir el estigma territorial de estos barrios, el que no sólo describen como un hecho, al tiempo también lo naturalizan sin un mayor esfuerzo por romper con este esquema. De alguna manera, los hechos de violencia que son mostrados a

40 Cornejo, 2011. 
través de los medios de comunicación y se integran al imaginario social, parecen justificar el estigma. Invisibilizan tanto el hecho de la diversidad social de sujetos en condición de pobreza, como también el hecho mismo que la calificación bajo los términos del estigma (y su reproducción) es un hecho violento. Así, los medios de comunicación contribuyen a la reproducción del estigma de habitantes de El Castillo. En este ámbito de los medios de comunicación reconocemos un campo abierto a la exploración de la creación y reproducción de las identidades sociales, particularmente de los estigmas sociales.

\section{Reflexiones finales}

En la literatura encontramos repetidamente la advertencia que la asociación entre violencia y los actos delictuales no es una cuestión necesaria. No obstante, al parecer a falta de mejores indicadores en las ciencias sociales, el delito se suele observar para medir los niveles de violencia de los países, ciudades, etc., en especial a través de las tasas de homicidio ${ }^{41}$. Este sesgo parece ser producto de una incapacidad teórico-metodológica de las ciencias

41 Incluso en autores críticos como Cooper (1999) identifican la violencia con el fenómeno delictual (el título de su presentación utilizada en este artículo es claro al respecto). sociales para observar la violencia, más que de características del fenómeno mismo.

De nuestra consideración, un elemento que ayuda a reforzar esta asociación entre violencia y delincuencia, con la consecuencia de notoriedad pública de los delitos violentos, es la creciente importancia que cobra la seguridad ciudadana en el ámbito de la política interior de los estados nacionales. Esto último no debe considerarse una causa por sí misma, también requiere una explicación. Una intuición al respecto es que el discurso sobre seguridad ciudadana, más allá del aumento objetivo de la violencia -por lo menos referido al homicidio en el concierto de los países latinoamericanos-, es legitimador del orden social, que viene a oscurecer las relaciones que tienen la violencia, la delincuencia (común) y las desigualdades sociales.

Lo anterior podemos alinearlo con la crítica de Loïc Wacquant al tratamiento teórico del gueto negro en USA por medio del concepto underclass, enfocado en 'las deficiencias de conducta y culturales' y en el 'impacto de agregado de la consolidación de un orden económico posindustrial', lo que ha terminado por ocultar las causas propiamente políticas del gueto y ha favorecido un aumento de 
'la estigmatización y aislamiento de político de sus residentes'. El concepto underclass separa el gueto de las estructuras sociopolíticas más generales de la dominación de casta y clase, a la vez, es uno de sus productos y un mecanismo central de la dominación ${ }^{42}$. Estas mismas conclusiones parecen ser útiles para hablar de la violencia restringida al fenómeno delictual. En otras palabras, la identificación de la violencia con la delincuencia y su importancia tanto a nivel de la opinión pública como de la academia tienen como contraparte el ocultamiento de las causas sociales de este fenómeno, sirviendo a la legitimación y reproducción del orden social, entre otros efectos.

En este punto, la respuesta a la pregunta acerca de la posibilidad de entender la violencia trascendiendo su vinculación con la delincuencia es afirmativa. Ese fue el desafío que enfrentamos al intentar explorar sobre este fenómeno más allá de su expresión física y delictual, como relaciones de fuerza que se expresan también en el plano simbólico. Ello no significa que la violencia esté desligada de una materialidad o territorialidad, incluso de la corporalidad de los sujetos. Es más, éstas sirven de medios y objetos referentes en los que se identifica y visibiliza la violencia en el discurso.

Entendemos que la estigmatización territorial responde a una forma de diferenciación identitaria y de constitución de alteridad, que surge no sólo del reconocimiento de las diferencias y desigualdades sino también por procesos de exclusión social, que se expresa tanto a nivel de la economía y la política, como a nivel de las representaciones sociales, teniendo repercusiones en la capacidad de los excluidos para representarse a sí mismos.

La exclusión también es observable en la segregación espacial de los grupos sociales. Para comprender desde esta perspectiva el caso observado, debemos remitirnos al programa de erradicación de campamentos que constituye una expulsión planificada de los habitantes pobres de la ciudad y violencia por parte del estado concretizada en el territorio (con propósitos como la desarticulación política de los movimientos de pobladores, entre otros).

Por otra parte, entre sus efectos se cuenta el incremento del valor del suelo en las zonas que se vieron "limpias" de campamentos. Parece interesante observar este último hecho a la luz de la externalidades, es decir, las diferencias entre los costes y/o beneficios sociales y privados del mercado del suelo. Como resulta evidente, las externalidades positivas se juegan a favor de los barrios más ricos de la ciudad, haciéndolos más atractivos dentro del mercado del suelo urbano. Como contracara encontramos a los barrios pobres y estigmatizados, como El Castillo.

42 Wacquant, 2001, p. 92-93. 
El estigma territorial que pesa sobre este sector, o sobre otros barrios de Santiago, parece encontrar aquí una de sus causas: la lógica del mercado. Así comprendemos que, en última instancia, el estigma opera conjuntamente en el territorio y en el ámbito simbólico, como resultado de violencia objetiva inherente al funcionamiento del orden social desigual y excluyente en la sociedad chilena.

\section{Bibliografía}

ABARCA, Humberto y SEPÚLVEDA, Mauricio. Barras Bravas, pasión guerrera. Territorio, masculinidad y violencia en el fútbol chileno. En: FERRÁNDIZ, Francisco y FEIXA, Carles, eds. Jóvenes sin tregua: culturas y políticas de la violencia. España, Antrophos. 2005. pp. 145-169. ISBN 9788476587294.

CORNEJO, Catalina. Segregación espacial y las prácticas espaciales de los excluidos. Estudio de caso: el sector El Castillo, de La Pintana. Santiago, Universidad de Chile. 2011. 116 p. Tesis para optar al título de Antropóloga social.

BARBER0, José Manuel. Desencuentros de la socialidad y reencantamientos de la identidad. Anàlisi: Quaderns de comunicació i cultura. (29): 45-62, 2002. ISSN 0211-2175.

Borja, Jordi y Muxi, Zaida. El espacio público: ciudad y ciudadanía. Barcelona, Electa. 2003. ISBN 8481563439.

198 revista invi № 76 / Noviembre 2012 / Volumen № 27: 177-200
BOURDIEU, Pierre. Fundamentos de una teoría de la violencia simbólica. En: Bourdieu, Pierre y Passeron, Jean-Claude. La Reproducción. Elementos para una teoría del sistema de enseñanza. España, Popular. 2001. p. 15-85. ISBN 9684765398.

BOURDIEU, Pierre. Razones prácticas. Sobre la teoría de la acción. Barcelona, Anagrama. 1997. 233 p. ISBN 84-339-0543-0. Colección Argumentos.

BUVINIC, Mayra, MORRISON, Andrew y ORLANDO, María. Violencia, crimen y desarrollo social en América Latina y el Caribe. [En línea]. Papeles de población. (43): 167-214, 2005. ISSN 1405-7425. Disponible en: http://redalyc.uaemex.mx/src/inicio/ArtPdfRed.jsp?iCve=11204309.

CAMPO TEJEDOR, Alberto del. Investigar y deconstruir el estigma en barrios marginales. Un estudio de caso. [En línea]. Zainak. Cuadernos de Antropología-Etnografía. (24): 803-817, 2003. ISSN $1137-$ 439X. Disponible en: http://www.euskomedia. org/PDFAnlt/zainak/24/08030817.pdf.

Carrion, Fernando. La violencia urbana y sus nuevos escenarios. [En línea]. Enlace: revista de la Escuela de Estado Mayor de la Policía Nacional del Ecuador. (3): 32-35, julio 2003. Disponible en: http:// works.bepress.com/fernando_carrion/195.

COOPER, Doris. Violencia urbana: la economía informal alternativa ilegal del hampa y las pandillas poblacionales. Trilogía. 18(28): 31-45, diciembre de 1999. ISSN 0716-0356. 
GOFFMAN, Erwin. Estigma: identidad deteriorada. Buenos Aires, Argentina, Amorrortu. 2006. 172 p. ISBN 10 950-518-016-0.

LABBÉ, Francisco y LLÉVENES, Marcelo. Efectos distributivos derivados del proceso de erradicación de poblaciones en el Gran Santiago. [En línea]. Estudios Públicos. (24): 199-242, 1986. [Fecha de consulta: 25 de agosto 2008] Disponible en: http:// www.cepchile.cl/dms/lang_1/doc_1571.html.

LEIVA, Claudio. Caen los vatos locos, peligrosa banda a sueldo. [En línea]. La Nación. 2010. Disponible en: http://www.lanacion.cl/caen-losvatos-locos-peligrosa-banda-a-sueldo/noticias/2010-03-24/192634.html.

LINK, Bruce G. y PHELAN, Jo C. Conceptualizing stigma. [En línea]. Annual Review of Sociology. 27: 363-85, 2001. ISSN 0360-0572. Disponible en http://dx.doi.org/10.1146/annurev.soc.27.1.363.

LUNECKE, Alejandra y RUIZ, Juan Carlos. Barrios urbanos críticos en materia de violencia y delincuencia: Marco de análisis para la construcción de indicadores de diagnóstico. Presentado en el $2^{\circ}$ Simposio sobre Violencia y Delincuencia. Paz Ciudadana - PUC. 2006. s/p.

MONTECINO, Sonia. Nuevas feminidades y masculinidades: una mirada de género al mundo evangélico de La Pintana. [En línea]. Estudios Públicos. (87): 73-103, 2002. [Fecha de consulta: 13 de junio 2011] Disponible en: www.cepchile.cl/dms/archivo_3140_1038/rev87_montecino.pdf
OLM0, Rosa del. Ciudades duras y violencia urbana. [En línea]. Nueva Sociedad. (167): 74-86, mayo 2000. [Fecha de consulta: 13 junio, 2011]. Disponible en: http://www.bvsde.paho.org/bvsacd/ cd26/foro.pdf.

OVIEDO, Enrique. Democracia y seguridad ciudadana en Chile. [En línea]. En: BRICEÑO-LEÓN, Roberto. Violencia, sociedad y justicia en América Latina. Buenos Aires, CLACSO. 2001. p. 313-338. ISBN 950-9231-81-98. Disponible en: http://biblioteca.clacso.edu.ar/ar/libros/violencia/oviedo. pdf.

RODRíGUEZ, Alberto e ICAZA, Ana María. Procesos de expulsión de habitantes de bajos ingresos del centro de Santiago, 1981-1990. [En línea]. Proposiciones. (22): 138-172, agosto 1993. [Fecha de consulta: 17 marzo 2010]. Disponible en: http:// www.sitiosur.cl/r.php?id=225.

RUIZ, Juan Carlos. Violencias en barrios críticos de Santiago: Narcotráfico y transformación del capital social en la periferia simbólica de la ciudad. Santiago, Pontificia Universidad Católica de Chile. 2008. Tesis para optar al grado de Magíster en Desarrollo Urbano.

SABATINI, Francisco; CÁCERES, Gonzalo y CERDA, José. Segregación espacial en las principales ciudades chilenas: tendencias de las últimas tres décadas y posibles cursos de acción. [En línea]. EURE. 27(82): 21-42, diciembre 2001. ISSN 02507161. Disponible en: http://dx.doi.org/10.4067/ S0250-71612001008200002.

revista invi № 76 / Noviembre 2012 / Volumen № 27: 177-200 199 
SABATINI, Francisco; WORMALD, Guillermo; SIERRALTA, Carlos y PETERS, Patricio. Segregación residencial en Santiago. Tendencias 1992-2002 y efectos vinculados con su escala geográfica. En: TENDENCIAS de la segregación en las principales ciudades chilenas. Santiago, Chile, INE-PUC. 2010. p. 19-41. ISBN 978-956-14-1110-4.

SECPLAC, Secretaría Comunal de Planificación. Guía de información, comuna La Pintana, I. Municipalidad de La Pintana. 2009.

SECPLAC, Secretaría Comunal de Planificación. Plan de desarrollo comunal 2012-2016. [En línea]. Plan de Desarrollo Comunal PLADECO. 2012. [Fecha de consulta: 19 mayo 2012]. Disponible en: http:// www.pintana.cl/transparencia/images/OtrasInfoMunicipal/PLADECO2012-2016.pdf.

TRAVERSO, Gianna. Historia y configuración socioespacial del sector El Castillo, comuna La Pintana: aproximación al ghetto en el estudio de la geografía social. Santiago, Departamento de Geografía, Universidad de Chile. 2006. Memoria para optar al título profesional de geógrafa.

WACQUANT, Loïc. Parias urbanos: marginalidad en la ciudad a comienzos del milenio. Buenos Aires, Manantial. 2001. 307 p. ISBN 9875000582.

WACQUANT, Loïc. Las dos caras de un gueto. La construcción de un concepto sociológico. [En línea]. Renglones. (56): 72-80, enero 2004. ISSN 01864963. Disponible en: http://renglones.iteso.mx/ upload/archivos/56_11_dos_caras.pdf.

WACQUANT, Loïc. The body, the ghetto and the penal state. [En línea]. Qualitative Sociology. 32(1): 101129, marzo 2009. Disponible en: http://dx.doi. org/10.1007/s11133-008-9112-2.

ZIZEC, Slavoj. Sobre la violencia: seis reflexiones marginales. Barcelona, España, PAIDÓS. 2009. 264 p. ISBN 978-84-493-2208-2. 